1 Short title: Grape seed extract and non-O157 Shiga toxin producing E. coli

3 Inhibitory effects of grape seed extract on growth, quorum sensing, and virulence factors of 4 CDC "top-six" non-O157 Shiga toxin producing $E$. coli

$7 \quad{ }^{1}$ School of Food Science, Washington State University, Pullman, WA 99164, USA; ${ }^{2}$ Department

8 of Animal Science, University of Wyoming, Laramie, WY 82071, USA; ${ }^{3}$ College of Animal

9 Science and Technology, Zhejiang Agriculture and Forestry University, Hangzhou 311300,

10 China

11 \#: These two authors have the same contribution.

$16 *$ Corresponding author:

17 Meijun Zhu, School of Food Science, Washington State university, Pullman, WA 99164; Email:

18 meijun.zhu@wsu.edu; Phone: 509-335-4016.

\title{
20 Acknowledgements
}

21 This work was supported by USDA-AFRI 2010-65201-20599 and an Emerging Research Issues

22 Internal Competitive Grant from the Washington State University, CAHNRS. 
Non-O157 Shiga toxin producing Escherichia coli (STEC) have become a growing concern to the food industry. Grape seed extract (GSE), a byproduct of wine industry, is 26 abundant in polyphenols that are known to be beneficial to health. The objectives of this study

27 were to evaluate the effect of GSE on the growth, quorum sensing, and virulence factors of 28 Centers for Disease Control and Prevention (CDC) "top-six" non-O157 STEC. Minimal 29 inhibitory concentration (MIC) of GSE was $2 \mathrm{mg} / \mathrm{ml}$ against E. coli O26:H11, and $4 \mathrm{mg} / \mathrm{ml}$ against the other non-O157 STEC tested. Minimal bactericidal concentration (MBC) was the 31 same as MIC for all six non-O157 STEC tested. At $5 \times 10^{5} \mathrm{CFU} / \mathrm{ml}$ inoculation level, $4 \mathrm{mg} / \mathrm{ml}$ 32 GSE effectively inhibited the growth of all tested strains, while $0.25-2 \mathrm{mg} / \mathrm{ml}$ GSE delayed 33 bacterial growth. At a higher inoculation level $\left(1 \times 10^{7} \mathrm{CFU} / \mathrm{ml}\right)$, GSE had less efficacy against 34 the growth of the selected six non-O157 STEC. Its impact on bacterial virulence was then 35 assessed at this inoculation level. Autoinducer-2 (AI-2) is a universal signal molecule mediating quorum sensing (QS). GSE at concentration as low as $0.5 \mathrm{mg} / \mathrm{ml}$ dramatically reduced AI-2

37 production of all non-O157 STEC tested, with the inhibitory effect proportional to GSE levels.

38 Consistent with diminished QS, GSE at concentration of $0.125 \mathrm{mg} / \mathrm{ml}$ caused marked reduction 39 of swimming motility of all motile non-O157 STEC tested. In agreement, GSE treatment 40 reduced the production of flagella protein FliC and its regulator FliA in E. coli O103:H2 and E. 41 coli O111:H2. Furthermore, $4 \mathrm{mg} / \mathrm{ml}$ GSE inhibited the production of Shiga toxin, a major 42 virulence factor, in E. coli $\mathrm{O} 103: \mathrm{H} 2$ and E. coli $\mathrm{O} 111: \mathrm{H} 2$. In summary, GSE inhibits the growth 43 of "top-six" non-O157 STEC at the population level relevant to food contamination. At higher 44 initial population, GSE suppresses QS with concomitant decrease in motility, flagella protein 
45 expression and Shiga toxin production. Thus, GSE has the potential to be used in food industry

46 to control non-O157 STEC.

47 Keywords: non-O157 STEC, GSE, growth, quorum sensing, motility, flagella, Shiga toxin

\section{Introduction}

Shiga toxin producing E. coli (STEC) are important zoonotic foodborne pathogens. Aside

51 from the well-recognized notorious serotype E. coli O157:H7, non-O157 STEC are of growing

52 food safety concern to the food industry and increasing importance to human infection due to

53 sporadic cases or outbreaks in the United States and globally (Hedican et al., 2009; Mathusa et

54 al., 2010). Non-O157 STEC are estimated to cause more than 110,000 cases of illness annually

55 throughout the United States, contributing to a larger portion of total STEC infections than $E$.

56 coli O157:H7 (Scallan et al., 2011). Centers for Disease Control and Prevention (CDC) has

57 designated six most common non-O157 STEC serogroups including O26, O45, O103, O111,

58 O121 and O145 as the "top-six" non-O157 STEC, which together account for more than $70 \%$ of

59 diseases caused by STEC that emerged from 1983 to 2002 (Brooks et al., 2005). Like notorious

60 E. coli O157:H7, non-O157 STEC infection can cause symptoms ranging from diarrhea and

61 hemorrhagic colitis, to fatal hemolytic uremic syndromes (HUS) and even death (Espie et al.,

62 2008; Hedican et al., 2009; Johnson et al., 2006; Mathusa et al., 2010).

Due to the increasing public health impact, the USDA-FSIS declared these "top-six" non-

64 O157 STEC serogroups as adulterants if present in non-intact raw beef products (Anonymous,

65 2011). In order to meet this requirement, meat industries are actively looking for effective

66 interventions to inactivate non-O157 STEC. For example, high pressure processing was used on

67 ground beef inoculated with the "top-six" non-O157 STEC cocktail; however, 5 Log reduction of 
bacteria was achieved only when processed at $450 \mathrm{MPa}$ for $15 \mathrm{~min}$ (Hsu et al., 2015). Spray

69 treatment of non-O157 STEC inoculated beef subprimal surfaces with commonly used

70 antimicrobials such as lactic acid and peroxyacetic acid only slightly reduced bacterial numbers

71 after 14 days storage (Liao et al., 2015). In addition, individual non-O157 STEC might be more

72 resistant to a particular intervention method. For example, E. coli O103 inoculated on fresh beef

73 flanks is less sensitive to hot water spray compared with either other non-O157 STEC or E. coli

74 O157:H7 strains (Kalchayanand et al., 2012). Therefore, developing effective intervention

75 methods for non-O157 strains is of great necessity.

bacterial growth. Grape seed extract (GSE) is a byproduct of wine and juice industry and rich in polyphenolic compounds that have received increasing attention for their health-beneficial effects (Kaur et al., 2009; Vislocky, Fernandez, 2010; Wang et al., 2013; Yang et al., 2015). Meanwhile, GSE is known for its antimicrobial activity against both gram-positive and gram-

81 negative bacteria including Staphylococcus aureus (Kao et al., 2010), Listeria monocytogenes

82 (Bisha et al., 2010; Rhodes et al., 2006), Vibrio parahaemolyticus (Mahmoud, 2014) and E. coli

83 O157:H7 (Ahn et al., 2007; Over et al., 2009). Previously, we reported that GSE inhibits the 84 growth of E. coli O157:H7 (Zhu et al., 2015). Up to now, there is no information regarding 85 efficacy of GSE in controlling non-O157 STEC. Here we assessed the effect of GSE on the 86 growth of the CDC's “top-six" non-O157 STEC. provides an alternative strategy for controlling foodborne pathogens. Quorum sensing (QS) is an

89 extracellular bacterial signaling that senses population density in the community through 
90

91

92

93

94

95

96

97

98

99

100

101

102

103

104

105

106

107

108

109

110

111

excreting autoinducer (AI) molecules, which orchestrates important events related to bacterial pathogenesis (Sperandio et al., 2001). QS in E. coli O157:H7 regulates flagellar synthesis and motility (Sperandio et al., 2002a), Shiga toxin (Stx) production (Sperandio et al., 2001), and expression of the type III secretion system (Sperandio et al., 1999). Thus, QS has been suggested as a global regulator controlling virulence factors as well as basic physiological function of $E$. coli O157:H7 (Sperandio et al., 2001). As a result, QS molecules are novel intervention targets to control foodborne pathogens. Therefore, the efficacy of GSE against QS and the motility of "topsix" non-O157 STEC as well as flagella and Stx production were further evaluated in this study.

\section{Materials and methods}

\subsection{Bacterial strains}

CDC “top-six" non-O157 STEC strains used in this study were obtained from the STEC center at Michigan State University (Table 1). The non-O157 STEC strains were routinely grown in $3 \mathrm{~mL} \mathrm{LB}$ broth or LB containing $0.5 \%$ (w/v) glucose (LBG) for quorum sensing assay in 10 $\mathrm{mL}$ glass test tubes at $37^{\circ} \mathrm{C}$ under shaking at $250 \mathrm{rpm}$ in MaxQ $\mathrm{Q}^{\mathrm{TM}} 4000$ Incubator Shaker (Thermo Scientific, Marietta, OH). Basic media (Diez-Gonzalez, Russell, 1999) with 0.4\% glucose (BMG) was then utilized in all experiments with GSE (Zhu et al., 2015). Vibrio harveyi was obtained from ATCC and grown in autoinducer bioassay (AB) medium at $30{ }^{\circ} \mathrm{C}$ with shaking at $250 \mathrm{rpm}$ in MaxQ $\mathrm{QM}^{\mathrm{TM}} 4000$ Incubator Shaker (Thermo Scientific).

\subsection{Grape seed extract}

GSE was purchased from Optipure (Los Angeles, CA) and it contains a minimum of 95\% total flavonols and $82 \%$ of proanthocyanidin. GSE stocking $(40 \mathrm{mg} / \mathrm{ml})$ solution was prepared in 
$11210 \%$ ethanol and microwaved for $5 \mathrm{~min}$ for the maximal extraction of phenolic compounds, and

113 then filter sterilized (Zhu et al., 2015).

1142.3 Minimal inhibitory concentration (MIC) and minimum bactericidal concentration (MBC)

115 MIC and MBC of GSE against all non-O157 STEC strains were determined as previously

116 described (Sheng, Zhu, 2014). Briefly, GSE stocking was added to BMG to a final concentration

117 of $16 \mathrm{mg} / \mathrm{ml}$, which was then 2-fold serial diluted in 96 well polystyrene microtiter plates

118 (Costar, Tewksbury, MA). The final tested GSE concentrations ranged from 0.03125 to 16

$119 \mathrm{mg} / \mathrm{ml}$. Each well was inoculated with $5 \times 10^{5} \mathrm{CFU} / \mathrm{ml}$ of non-O157 STEC. Cultures were

120 incubated statically at $37{ }^{\circ} \mathrm{C}$. MIC was determined as the lowest concentration of GSE that

121 inhibited bacterial growth as measured by optical density (OD) values at $600 \mathrm{~nm}$ at $24 \mathrm{~h}$

122 incubation. Samples from wells without visible growth were spread on LB agar plates and

123 incubated at $37^{\circ} \mathrm{C}$ for $24 \mathrm{~h}$. MBC was defined as the lowest concentration that inhibited bacterial

124 growth on the LB agar plates ( $<10 \mathrm{CFU} /$ plate was regarded as no growth). Experiments were

125 repeated three times with twice activated fresh culture.

\subsection{Growth curves}

Overnight STEC cultures were diluted in BMG with variable GSE concentrations to

128 achieve $1 \times 10^{7}$ or $5 \times 10^{5} \mathrm{CFU} / \mathrm{ml}$, and $200 \mu \mathrm{l}$ of bacterial suspension was added to 96 well

129 microtiter plates (Costar), and incubated statically at $37^{\circ} \mathrm{C}$. One column per treatment, 6 inner

130 wells of each column were inoculated with bacteria, while the two outside wells of each column

131 were loaded with BMG with respective GSE concentration. OD values were read hourly at 600

132 nm using SM5 spectrometer (Molecular Device, Sunnyvale, CA). The experiments were

133 repeated three times with fresh activated culture. 
AI-2 assay was performed as described previously (Surette, Bassler, 1998). Briefly, nonO157 STEC at $1 \times 10^{7} \mathrm{CFU} / \mathrm{ml}$ were cultured in BMG with various concentrations of GSE for $5 \mathrm{~h}$

137 at $37{ }^{\circ} \mathrm{C}$ under shaking at $250 \mathrm{rpm}$. Then the bacterial cultures were sampled for $\mathrm{CFU}$

138 enumeration, and the remaining cultures were centrifuged at $20,000 \times \mathrm{g}$ for $5 \mathrm{~min}$. The resulting

139 supernatant was harvested and incubated with $V$. harveyi in $96-$ well microtiter plates at $30{ }^{\circ} \mathrm{C} /$

$140250 \mathrm{rpm}$ for 5 h. V. harveyi was chosen as an indicator microorganism because it can express

141 bioluminescence in response to AI-2 produced either by itself or by other bacteria (Bassler et al.,

142 1997). Therefore, light production was measured using a BioTek microplate reader (Synergy H1,

143 BioTek). V. harveyi incubated with various tested concentrations of GSE was used as negative

144 control. Luminescence value of treatments was subtracted by corresponding luminescence value

145 of negative control to rule out negative influence of GSE itself on $V$. harveyi AI-2 production.

146 Results were normalized to control. This experiment was repeated three times with fresh

147 activated culture.

148

149

150

151

152

153

154

155

156

\subsection{Swimming motility assays}

Swimming motility was measured according to the previously published method (Zhu et al., 2015). Briefly, overnight cultures of respective non-O157 STEC were concentrated 10 times, and then 1:1 mixed with various concentrations of GSE solutions. Then, $5 \mu \mathrm{L}$ of respective nonO157 preparation was inoculated onto $0.25 \%$ LB soft agar plates containing $0,0.125,0.25$ or $0.50 \mathrm{mg} / \mathrm{ml} \mathrm{GSE}$, which were then incubated at $37^{\circ} \mathrm{C}$ for $6 \mathrm{~h}$. Motility was measured as the diameter of the swimming zone in millimeters. A diameter of $2 \mathrm{~mm}$ is considered as "no motility" as that is the diameter of the initial inoculation. The experiments were performed three times with fresh activated culture. 
Overnight E. coli $\mathrm{O} 103: \mathrm{H} 2$ and E. coli $\mathrm{O} 111: \mathrm{H} 2$ cultures were subcultured at $\sim 1 \times 10^{7}$

$159 \mathrm{CFU} / \mathrm{ml}$ in BMG with various GSE concentrations for $5 \mathrm{~h}$ at $37^{\circ} \mathrm{C}$ under shaking at $250 \mathrm{rpm}$.

160 Then cultures were sampled for CFU enumeration and protein sample preparation for analyzing

161 Stx2A, FliA, and FliC according to published methods (Zhu et al., 2015). Briefly, the above

162 bacteria preparation was 5:1 mixed with $6 \times$ SDS-PAGE sample lysis buffer and boiled for 15

163 min to lyse the bacteria and denature protein. Immunoblotting was conducted as previously

164 described (Zhu et al., 2015). Briefly, bacterial protein samples were separated by 10\% (w/v) SDS

165 polyacrylamide gels, transferred to nitrocellulose membrane, subjected to primary and secondary

166 antibody incubation, and ECL incubation (GE Healthcare, Buckinghamshire, UK) for band

167 visualization. Primary antibody against Stx2A (Toxin Tech. Inc., Sarasota, FL), FliA and FliC

168 (BioLegend, San Diego, CA) were used at 1:1000 dilution. The density of the target protein

169 bands was normalized to that of control group without GSE treatment. The relative values were

170 compared among GSE treatments and reported. The experiment was repeated three times with

171 fresh activated culture.

\section{3. Results}

\subsection{GSE inhibited the growth of non-O157 STEC}

175 MIC was determined to be $2 \mathrm{mg} / \mathrm{ml} \mathrm{GSE}$ for E. coli $\mathrm{O} 26: \mathrm{H} 11$ and $4 \mathrm{mg} / \mathrm{ml}$ for the other 176 non-O157 STEC tested (Table 1). MBC was the same with MIC for all the six non-O157 STEC 177 (Table 1). 
At an initial population of $5 \times 10^{5} \mathrm{CFU} / \mathrm{ml}, 4 \mathrm{mg} / \mathrm{ml}$ GSE completely inhibited growth of

179 all six strains up to $16 \mathrm{~h}$ (Fig. 1A-F). For E. coli O26:H11, 0.125 and $0.25 \mathrm{mg} / \mathrm{ml}$ GSE

180 prolonged bacterial lag phase in a dose dependent manner, and 0.5-4 mg/ml GSE inhibited

181 bacterial growth for at least $17 \mathrm{~h}$ (Fig. 1A). For E. coli O45:H2 and E. coli O121:H19, 0.125-0.5

$182 \mathrm{mg} / \mathrm{ml}$ GSE failed to show any inhibitory effect on bacterial growth while 1-4 mg/ml GSE

183 inhibited bacterial growth in a dose dependent manner (Fig. 1B\&E). Interestingly, GSE at

184 concentrations between $0.125-1 \mathrm{mg} / \mathrm{ml}$ enhanced the growth of E. coli O103: H2 and E. coli

185 O111:H2 (Fig. 1C\&D). GSE at all concentrations inhibited the growth of E. coli O145:NT for at 186 least $15 \mathrm{~h}$ (Fig. 1F).

At an initial population of $1 \times 10^{7} \mathrm{CFU} / \mathrm{ml}$, the growth of $E$. coli $\mathrm{O} 26: \mathrm{H} 11$ was the most affected by GSE; as low as $0.5 \mathrm{mg} / \mathrm{ml}$ GSE significantly stunted bacterial growth (Fig. 2A). For

189 the growth of $E$. coli $\mathrm{O} 45: \mathrm{H} 2$ and $E$. coli O145:NT, inhibitory effect of GSE increased 190 proportionally to its concentrations (Fig. 2B\&F). All tested concentrations of GSE exhibited 191 similar effects on E. coli O103:H2 growth, with no inhibitory effect until 9 h incubation (Fig. 192 2C). For E. coli O111:H2, 0.5-1mg/ml GSE showed little effect on bacterial growth while 2 and $1934 \mathrm{mg} / \mathrm{ml}$ GSE slightly inhibited bacterial growth (Fig. 2D). GSE had minimal inhibitory effect 194 against E. coli O121:H19 (Fig. 2E)

\subsection{GSE inhibited quorum sensing in non-O157 STEC}

AI-2 is a universal QS signal used by a variety of bacteria for communication and is a

197 global regulator of virulence factors in E. coli O157:H7 (Sperandio et al., 2001). GSE inhibited

198 AI-2 production of selected "top-six" non-O157 STEC in a similar pattern and in a dose

199 dependent manner (Fig. 3), while 0.5-4 mg/ml GSE had limited inhibitory effects on bacteria

200 growth except E. coli O26:H11 at 5h of incubation (Fig. 3). QS of E. coli O26:H11 was the least 
201 sensitive to GSE. $0.5 \mathrm{mg} / \mathrm{ml}$ GSE reduced the AI-2 production of E. coli O26:H11 to $20 \%$ of

202 the untreated cells (Fig. 3A), while to $\sim 10 \%$ of the untreated cells for the other bacteria (Fig. 3B-

203 F). AI-2 production in 1-4 mg/ml GSE treated groups was dramatically reduced for all non-O157

204 STEC tested (Fig. 3).

\subsection{GSE inhibited flagella motility of non-O157 STEC}

Flagella mediated motility is an important virulence factor for many foodborne

207 pathogens, and it is essential for bacterial biofilm formation, adhesion to epithelial cells, and

208 intestinal colonization (Duan et al., 2013). Motility is also of great importance to the food

209 industry since it increases the ability of bacteria to infect a larger surface area, such as the surface

210 of food processing equipment (O'May, Tufenkji, 2011). Thus, inhibitory effect of GSE against

211 flagella motility was further assessed. Based on the motility halo size, E. coli $\mathrm{O} 111: \mathrm{H} 2$ is the

212 most motile, while E. coli O26:H11 is the least motile (Fig. 4). GSE was effective in reducing

213 swimming motility of all the tested non-O157 STECs in a dose dependent manner. Including

$2140.125 \mathrm{mg} / \mathrm{ml}$ GSE in a swimming agar plate completely inhibited motility of tested non-O157

215 STEC except E. coli O111:H2 (Fig. 4). 0.125, 0.25 and $0.5 \mathrm{mg} / \mathrm{ml}$ of GSE reduced the motility

216 of E. coli $\mathrm{O} 111: \mathrm{H} 2$ by $30 \%, 65 \%$ and $100 \%$, respectively.

\subsection{GSE inhibited flagella protein and Stx production}

218 Shiga toxin (Stx) is one of the major virulence factors of STEC causing bloody diarrhea

219 and fatal hemolytic uremic syndrome (HUS) (Karmali et al., 1983). Flagella are mainly

220 responsible for the swimming motility. Epidemiological studies have shown that E. coli

221 O103:H2 and E. coli O111:H2 of "top-six" non-O157 serotypes are more frequently involved in 
222 outbreaks (Johnson et al., 2006; Luna-Gierke et al., 2014). Therefore, they were chosen to further

223 test effects of GSE on flagella and its major regulatory proteins as well as Stx2 production.

224 Consistent with stunted motility, GSE as low as $0.5 \mathrm{mg} / \mathrm{ml}$ reduced FliC production of

225 both E. coli O103:H2 and E. coli O111:H2 to undetectable level (Fig. 5C\&D). Furthermore, 0.5-

$2264 \mathrm{mg} / \mathrm{ml}$ GSE inhibited FliA production of E. coli O103:H2 to under detection level (Fig. 5E).

227 E. coli $\mathrm{O} 111: \mathrm{H} 2$ was less sensitive to GSE in FliA production. However, $0.5 \mathrm{mg} / \mathrm{ml}$ GSE

228 significantly reduced FliA production of E. coli $\mathrm{O} 111: \mathrm{H} 2$, and this inhibitory effect strengthened 229 with the increase of GSE concentrations (Fig. 5F).

230 In addition, $4 \mathrm{mg} / \mathrm{ml}$ GSE significantly reduced Stx2 production of both E. coli $\mathrm{O} 103: \mathrm{H} 2$ 231 and E. coli O111:H2 (Fig. 6C\&D). For E. coli O103:H2, 0.5-2 mg/ml GSE increased Stx2 232 production, but Stx2 production was not different among 0.5-2 mg/ml GSE treatments (Fig. 6C).

233 For E. coli O111:H2, GSE reduced Stx2 production in all tested concentrations with $4 \mathrm{mg} / \mathrm{ml}$ 234 GSE to be the most effective (Fig. 6D).

\section{Discussion}

GSE is a by-product of the wine industry, with abundant polyphenolic compounds known

238 for their anti-inflammatory and anti-oxidative effects (Wang et al., 2011). A wide variety of 239 studies examined their clinical potential, both in terms of disease prevention and treatment (Kaur

240 et al., 2009; Vislocky, Fernandez, 2010; Wang et al., 2013; Yang et al., 2015). Meanwhile, GSE

241 has shown inhibitory effect against a variety of pathogens including E. coli O157:H7 (Zhu et al.,

242 2015), L. monocytogenes (Bisha et al., 2010), and V. parahaemolyticus (Mahmoud, 2014). No

243 study has been conducted on non-O157 STEC thus far. Given that non-O157 STEC are of 
244 growing concern for the food industries of both the United States and worldwide, the objective of

245 this study was to assess the antimicrobial efficacy of GSE on the CDC's "top-six" non-O157

246 STEC.

Inhibitory effect of GSE against the growth of non-O157 STECs was population,

248 concentration, and strain dependent. At the low inoculation level, $4 \mathrm{mg} / \mathrm{ml}$ of GSE showed great

249 inhibitory effect against all the "top-six" non-O157 STEC, similar to the effect of GSE on E. coli

250 O157:H7 (Zhu et al., 2015). Mechanism of this antimicrobial effect might include disruption of

251 cytoplasmic membrane, inhibition of extracellular enzymes, binding of vital compounds for

252 bacterial metabolism, and others (Walsh et al., 2003). Interestingly, lower concentrations of GSE

253 promoted the growth of E. coli $\mathrm{O} 103: \mathrm{H} 2$ and E. coli $\mathrm{O} 111: \mathrm{H} 2$. Similar phenomenon was also

254 seen in E. coli O157:H7 when GSE (Zhu et al., 2015), broccoli extract (Lee et al., 2011b), and

255 honey (Lee et al., 2011a) were used at low concentrations. It is probably due to the competition

256 between the growth promotion effect of nutrients and the growth inhibition effect of the

257 polyphenols in GSE. At the high initial population, GSE showed limited effect against most

258 bacterial growth.

259 Mediated by autoinducer molecules, QS is a crucial signaling regulating motility and

260 virulence factors in pathogenic bacteria including E. coli O157:H7 (Sperandio et al., 2001).

261 Thus, QS has emerged as a promising target for eliminating or alleviating bacterial virulence.

262 However, the role of QS in non-O157 STEC virulence has not been uncovered, let alone QS

263 regulation by natural antimicrobials including GSE. Our results, for the first time indicated that

264 GSE effectively inhibited the "universal" signal molecule AI-2 levels of all six non-O157 STEC

265 tested. In agreement with regulatory role of QS in motility of E. coli O157:H7 (Sperandio et al., 

2002b) and reduced QS observed in GSE treated bacteria, GSE effectively reduced swimming

267 motility of all six non-O157 STEC tested. In line with that, polyphenolic compounds derived

268 from algae and green tea, brominated furanone and epigallocatechin gallate, reduced AI-2

269 production and motility in Campylobacter jejuni (Castillo et al., 2015). Furthermore, 0.5\%

270 broccoli extract suppressed AI-2 production and motility of E. coli O157:H7 (Lee et al., 2011b).

271 QS regulates bacterial motility and pathogen virulence, both of which are critically

272 important to the food industry. Flagella are mainly responsible for motility. In E. coli, the

273 expression of flagella genes is in a hierarchical manner (Macnab, 2003). Induction of master

274 flagella regulator FlhDC activates a transcription regulator FliA, which further regulates

275 expression of genes encoding the key structural component of the flagellum filament FliC

276 (Chilcott, Hughes, 2000; Macnab, 2003). Consistent with the reduced motility, GSE effectively

277 reduced key the flagella protein FliC as well as its regulator FliA in both E. coli O103:H2 and E.

278 coli O111:H2. In support of our finding, E. coli mutant strain defective in AI-2 production

279 showed lower FliC gene expression compared with wild type strain (Soni et al., 2007), while

280 addition of AI-2 restored the expression of FliA and FliC (Lee et al., 2008). These findings

281 suggested that QS might play an important role in the motility as well as flagella production of 282 non-O157 STEC. Furthermore, there is a strain dependent effect in response to GSE treatment 283 among non-O157 STEC. E. coli O111:H2 was least sensitive to GSE in regards to swimming 284 motility. Of note, GSE is rich in polyphenols, which are known to bind relatively strongly to 285 proteins and to cause aggregation of proteins. Thus, the inhibition of motility might also due to 286 binding of GSE to flagellar protein directly. 
Shiga toxin (Stx) is one of the major virulence factors contributing to the pathogenicity of non-O157 STEC, causing symptoms from mild diarrhea to hemolytic uremic syndrome (HUS) and even death (Johnson et al., 2006). QS plays a positive role in Stx production of E. coli

290 O157:H7 (Sperandio et al., 2001). Consistent with reduced AI-2 production in E. coli O103:H2

291 E. coli $\mathrm{O} 111: \mathrm{H} 2, \mathrm{GSE}$ at all tested concentration inhibited Stx2 production in E. coli $\mathrm{O} 111: \mathrm{H} 2$, 292 with higher doses having more profound effects. In E. coli O103:H2, 4mg/ml of GSE reduced 293 Stx2 production, which is in agreement with diminished AI-2 production. Interestingly, Stx2 294 production in E. coli $\mathrm{O} 103: \mathrm{H} 2$ was increased in response to $0.5-2 \mathrm{mg} / \mathrm{ml}$ of GSE treatment, which 295 is in contrast to decreased AI-2 production. These observations are similar to our findings on 296 Stx2 level of E. coli O157:H7 upon low concentrations of GSE treatment (Zhu et al., 2015). 297 Meanwhile, it highlights the complex nature of Stx2 production among non-O157 STEC, which 298 may not be solely regulated by AI-2 production. Study also indicates that antimicrobial 299 resistance in non-O157 is serogroup and Shiga toxin genotype dependent. For instance, in a 300 study on antimicrobial efficacy of fosfomycin against 11 strains of O26 isolated from cattle, MIC 301 was ranged from 2 to $32 \mathrm{mg} / \mathrm{L}$ depending on serotype; one strain was even resistant to 302 fosfomycin (Sasaki et al., 2012). Therefore, more studies are needed to assess the effects of GSE 303 on the growth and virulence of other non-O157 STEC not tested in this study. In conclusion, GSE inhibits the growth of the selected CDC "top-six" non-O157 STEC at 305 a population level of $5 \times 10^{5} \mathrm{CFU} / \mathrm{ml}$. At higher population, GSE suppresses AI-2 production, 306 motility and Stx production of the non-O157 STEC tested with minor effect on bacterial growth.

307 Taken together, GSE is an effective antimicrobial to control non-O157 STEC tested via 308 inhibiting both growth and virulence. 
310 Table $1 \mathrm{MIC}$ and MBC of grape seed extract for CDC top-six non-O157 Shiga toxin producing 311 E. coli (STEC)

\begin{tabular}{lccc}
\hline E. coli serotype & Isolate & MIC $^{2}$ & MBC $^{\mathbf{3}}$ \\
\hline E. coli $\mathrm{O} 26: \mathrm{H} 11^{1}$ & $97-3250$ & $2 \mathrm{mg} / \mathrm{ml}$ & $2 \mathrm{mg} / \mathrm{ml}$ \\
E. coli $\mathrm{O} 45: \mathrm{H}^{1}$ & $\mathrm{DA}-21$ & $4 \mathrm{mg} / \mathrm{ml}$ & $4 \mathrm{mg} / \mathrm{ml}$ \\
E. coli $\mathrm{O} 103: \mathrm{H}^{1}$ & $\mathrm{MT} \# 80$ & $4 \mathrm{mg} / \mathrm{ml}$ & $4 \mathrm{mg} / \mathrm{ml}$ \\
E. coli $\mathrm{O} 111: \mathrm{H}^{1}$ & $\mathrm{RD} 8$ & $4 \mathrm{mg} / \mathrm{ml}$ & $4 \mathrm{mg} / \mathrm{ml}$ \\
E. coli $\mathrm{O} 121: \mathrm{H} 19^{1}$ & $\mathrm{MT \# 2}$ & $4 \mathrm{mg} / \mathrm{ml}$ & $4 \mathrm{mg} / \mathrm{ml}$ \\
E. coli $\mathrm{O} 145: \mathrm{NT}^{1}$ & $\mathrm{IH} 16$ & $4 \mathrm{mg} / \mathrm{ml}$ & $4 \mathrm{mg} / \mathrm{ml}$ \\
\hline
\end{tabular}

${ }^{1}$ The strain has human origin and was obtained from STEC center, Michigan State University, East Lansing, MI 48824; ${ }^{2} \mathrm{MIC}$ : minimum inhibitory concentration; ${ }^{3} \mathrm{MBC}$ : minimum bactericidal concentration 


\section{Figure legends}

319 Figure 1. Growth curves of the selected CDC "top-six" non-O157 Shiga toxin producing E. coli 320 strains in basic growth media with $0.4 \%$ glucose under various GSE concentrations and $5 \times 10^{5}$

$321 \mathrm{CFU} / \mathrm{ml}$ initial inoculation population at $37^{\circ} \mathrm{C}$. (A) E. coli O26: H11; (B) E. coli O45: H2; (C) 322 E. coli O103: H2; (D) E. coli O111: H2; (E) E. coli O121: H19; (F) E. coli O145: NT. (Mean \pm 323 SEM, $\mathrm{n}=3$ ).

Figure 2. Growth curves of the selected "top-six" non-O157 Shiga toxin producing E. coli 326 strains in basic growth media with $0.4 \%$ glucose under various GSE concentrations and $1 \times 10^{7}$ $327 \mathrm{CFU} / \mathrm{ml}$ initial inoculation population at $37^{\circ} \mathrm{C}$. (A) E. coli O26: H11; (B) E. coli O45: H2; (C) 328 E. coli O103: H2; (D) E. coli O111: H2; (E) E. coli O121: H19; (F) E. coli O145: NT. (Mean \pm 329 SEM, $\mathrm{n}=3$ ).

331 Figure 3. CFU enumeration and AI-2 production of six non-O157 STEC in BMG with varying 332 concentrations of $\mathrm{GSE}$ at $37^{\circ} \mathrm{C}$ with initial inoculation population $1 \times 10^{7} \mathrm{CFU} / \mathrm{ml}$ after $5 \mathrm{~h}$ 333 incubation (Mean \pm SEM; N=3). (A) E. coli O26: H11 (up: $\log _{10}$ CFU, down: AI-2 production);

334 (B) E. coli O45: H2 (up: $\log _{10}$ CFU, down: AI-2 production); (C) E. coli O103: H2 (up: $\log _{10}$ 335 CFU, down: AI-2 production); (D) E. coli O111: H2 (up: Log 10 CFU, down: AI-2 production); 336 (E) E. coli O121: H19 (up: $\log _{10}$ CFU, down: AI-2 production); (F) E. coli O145: NT (up: $\log _{10}$ 337 CFU, down: AI-2 production). 
339 Figure 4. Swimming motility of selected "top-six" non-O157 STEC on $0.25 \%$ LB soft agar

340 plates with various GSE concentrations. Swimming zones were measured $6 \mathrm{~h}$ post-incubation at

$34137^{\circ} \mathrm{C} .($ Mean \pm SEM; $\mathrm{n}=3)$.

343 Figure 5. Effect of GSE on FliA and FliC production in E. coli O103:H2 and E. coli O111:H2.

344 Bacteria with initial inoculation population of $1 \times 10^{7} \mathrm{CFU} / \mathrm{ml}$ were incubated with GSE for $5 \mathrm{~h}$ in 345 BMG and protein concentrations were analyzed by immunoblotting. (A) $\log _{10}$ CFU of E. coli 346 O103:H2 after $5 \mathrm{~h}$ incubation in BMG with GSE. (B) $\log _{10} \mathrm{CFU}$ of E. coli $\mathrm{O} 111: \mathrm{H} 2$ after $5 \mathrm{~h}$ 347 incubation in BMG with GSE. (C) FliC production of $E$. coli O103:H2. (D) FliC production of $E$. 348 coli $\mathrm{O} 111: \mathrm{H} 2$ (E) FliA production of E. coli $\mathrm{O} 103: \mathrm{H} 2$. (F) FliA production of E. coli $\mathrm{O} 111: \mathrm{H} 2$. 349 (Mean \pm SEM; $\mathrm{n}=3)$.

351 Figure 6. Effect of GSE on Stx2 production of E. coli $\mathrm{O} 103: \mathrm{H} 2$ and E. coli $\mathrm{O} 111: \mathrm{H} 2$. Bacteria 352 with initial inoculation population of $1 \times 10^{7} \mathrm{CFU} / \mathrm{ml}$ were incubated with GSE for $5 \mathrm{~h}$ in BMG 353 and protein concentrations were analyzed by immunoblotting. (A) $\log _{10}$ CFU of E. coli

354 O103:H2 after 5 h incubation in BMG with GSE. (B) $\log _{10} \mathrm{CFU}$ of E. coli O111:H2 after $5 \mathrm{~h}$

355 incubation in BMG with GSE. (C) E. coli O103:H2 Stx2 production. (D) E. coli O111:H2 Stx2 356 production. (Mean $\pm \mathrm{SEM} ; \mathrm{n}=3$ ). 


\section{Reference}

360 Ahn, J., Grun, I.U., Mustapha, A. 2007. Effects of plant extracts on microbial growth, color 361 change, and lipid oxidation in cooked beef. Food Microbiol 24, 7-14. Anonymous. 2011. Shiga toxin-producing Escherichia coli in certain raw beef products. Federal Register 76, 58157-58165.

Bassler, B.L., Greenberg, E.P., Stevens, A.M. 1997. Cross-species induction of luminescence in the quorum-sensing bacterium Vibrio harveyi. J Bacteriol 179, 4043-4045.

Bisha, B., Weinsetel, N., Brehm-Stecher, B.F., Mendonca, A. 2010. Antilisterial effects of gravinol-s grape seed extract at low levels in aqueous media and its potential application as a produce wash. J Food Prot 73, 266-273.

Brooks, J.T., Sowers, E.G., Wells, J.G., Greene, K.D., Griffin, P.M., Hoekstra, R.M., Strockbine, N.A. 2005. Non-O157 Shiga toxin-producing Escherichia coli infections in the United States, 1983-2002. J Infect Dis 192, 1422-1429.

Castillo, S., Heredia, N., Garcia, S. 2015. 2(5H)-Furanone, epigallocatechin gallate, and a citricbased disinfectant disturb quorum-sensing activity and reduce motility and biofilm formation of Campylobacter jejuni. Folia Microbiologica 60, 89-95.

Chilcott, G.S., Hughes, K.T. 2000. Coupling of flagellar gene expression to flagellar assembly in Salmonella enterica serovar typhimurium and Escherichia coli. Microbiology and molecular biology reviews : MMBR 64, 694-708.

Diez-Gonzalez, F., Russell, J.B. 1999. Factors affecting the extreme acid resistance of Escherichia coli O157:H7. Food Microbiol 16, 367-374.

Duan, Q., Zhou, M., Zhu, L., Zhu, G. 2013. Flagella and bacterial pathogenicity. J Basic Microbiol 53, 1-8.

Espie, E., Grimont, F., Mariani-Kurkdjian, P., Bouvet, P., Haeghebaert, S., Filliol, I., Loirat, C., Decludt, B., Minh, N.N., Vaillant, V., de Valk, H. 2008. Surveillance of hemolytic uremic syndrome in children less than 15 years of age, a system to monitor O157 and non-O157 Shiga toxin-producing Escherichia coli infections in France, 1996-2006. Pediatr Infect Dis J 27, 595601.

Hedican, E.B., Medus, C., Besser, J.M., Juni, B.A., Koziol, B., Taylor, C., Smith, K.E. 2009. Characteristics of O157 versus non-O157 Shiga toxin-producing Escherichia coli infections in Minnesota, 2000-2006. Clin Infect Dis 49, 358-364.

Hsu, H., Sheen, S., Sites, J., Cassidy, J., Scullen, B., Sommers, C. 2015. Effect of high pressure processing on the survival of Shiga toxin-producing Escherichia coli (Big Six vs. O157:H7) in ground beef. Food Microbiol 48, 1-7.

Johnson, K.E., Thorpe, C.M., Sears, C.L. 2006. The emerging clinical importance of non-O157 Shiga toxin-producing Escherichia coli. Clin Infect Dis 43, 1587-1595.

Kalchayanand, N., Arthur, T.M., Bosilevac, J.M., Schmidt, J.W., Wang, R., Shackelford, S.D., Wheeler, T.L. 2012. Evaluation of commonly used antimicrobial interventions for fresh beef inoculated with Shiga toxin-producing Escherichia coli serotypes O26, O45, O103, O111, O121, O145, and O157:H7. J Food Prot 75, 1207-1212. 
Kao, T.T., Tu, H.C., Chang, W.N., Chen, B.H., Shi, Y.Y., Chang, T.C., Fu, T.F. 2010. Grape seed extract inhibits the growth and pathogenicity of Staphylococcus aureus by interfering with dihydrofolate reductase activity and folate-mediated one-carbon metabolism. Int J Food Microbiol 141, 17-27. syndrome associated with faecal cytotoxin and cytotoxin-producing Escherichia coli in stools. Lancet 1, 619-620.

Kaur, M., Agarwal, C., Agarwal, R. 2009. Anticancer and cancer chemopreventive potential of grape seed extract and other grape-based products. J Nutr 139, 1806S-1812S. concentrations of honey reduce biofilm formation, quorum sensing, and virulence in Escherichia coli O157: H7. Biofouling 27, 1095-1104.

Lee, J., Zhang, X.S., Hegde, M., Bentley, W.E., Jayaraman, A., Wood, T.K. 2008. Indole cell signaling occurs primarily at low temperatures in Escherichia coli. The ISME journal 2, 10071023. 2011b. Inhibitory effects of broccoli extract on Escherichia coli O157:H7 quorum sensing and in vivo virulence. FEMS Microbiol Lett 321, 67-74. Liao, Y.T., Brooks, J.C., Martin, J.N., Echeverry, A., Loneragan, G.H., Brashears, M.M. 2015. Antimicrobial interventions for O157:H7 and non-O157 Shiga toxin-producing Escherichia coli on beef subprimal and mechanically tenderized steaks. J Food Prot 78, 511-517. R.K. 2014. Outbreaks of non-O157 Shiga toxin-producing Escherichia coli infection: USA. Epidemiol Infect 142, 2270-2280.

Macnab, R.M. 2003. How bacteria assemble flagella. Annual review of microbiology 57, 77 100.

Mahmoud, B.S.M. 2014. The efficacy of grape seed extract, citric acid and lactic acid on the inactivation of Vibrio parahaemolyticus in shucked oysters. Food Control 41, 13-16.

Mathusa, E.C., Chen, Y., Enache, E., Hontz, L. 2010. Non-O157 Shiga toxin-producing Escherichia coli in foods. J Food Prot 73, 1721-1736.

O'May, C., Tufenkji, N. 2011. The swarming motility of Pseudomonas aeruginosa is blocked by cranberry proanthocyanidins and other tannin-containing materials. Appl Environ Microbiol 77, 3061-3067.

Over, K.F., Hettiarachchy, N., Johnson, M.G., Davis, B. 2009. Effect of organic acids and plant extracts on Escherichia coli O157:H7, Listeria monocytogenes, and Salmonella Typhimurium in broth culture model and chicken meat systems. J Food Sci Eng 74, M515-521.

Rhodes, P.L., Mitchell, J.W., Wilson, M.W., Melton, L.D. 2006. Antilisterial activity of grape juice and grape extracts derived from Vitis vinifera variety Ribier. Int J Food Microbiol 107, 281-286. 
Sasaki, Y., Usui, M., Murakami, M., Haruna, M., Kojima, A., Asai, T., Yamada, Y. 2012. Antimicrobial resistance in Shiga toxin-producing Escherichia coli $\mathrm{O} 157$ and $\mathrm{O} 26$ isolates from beef cattle. Jpn J Infect Dis 65, 117-121.

441 Scallan, E., Hoekstra, R.M., Angulo, F.J., Tauxe, R.V., Widdowson, M.A., Roy, S.L., Jones, 442 J.L., Griffin, P.M. 2011. Foodborne illness acquired in the United States-major pathogens. Emerg Infect Dis 17, 7-15.

Sheng, L., Zhu, M.-J. 2014. Inhibitory effect of Cinnamomum cassia oil on non-O157 Shiga toxin-producing Escherichia coli. Food Control 46, 374-381.

Soni, K., Jesudhasan, P., Cepeda, M., Williams, B., Hume, M., Russell, W.K., Jayaraman, A., Pillai, S.D. 2007. Proteomic analysis to identify the role of LuxS/AI-2 mediated protein expression in Escherichia coli O157:H7. Foodborne Pathog Dis 4, 463-471.

Sperandio, V., Li, C.C., Kaper, J.B. 2002a. Quorum-sensing Escherichia coli regulator A: a regulator of the LysR family involved in the regulation of the locus of enterocyte effacement pathogenicity island in enterohemorrhagic E. coli. Infection and Immunity 70, 3085-3093. expression of the type III secretion gene transcription and protein secretion in enterohemorrhagic and enteropathogenic Escherichia coli. Proc Natl Acad Sci U S A 96, 15196-15201.

Sperandio, V., Torres, A.G., Giron, J.A., Kaper, J.B. 2001. Quorum sensing is a global 5197. and $\mathrm{C}$ (QseBC): a novel two-component regulatory system involved in the regulation of flagella and motility by quorum sensing in E. coli. Mol Microbiol 43, 809-821.

Vislocky, L.M., Fernandez, M.L. 2010. Biomedical effects of grape products. Nutr Rev 68, 656670.

Walsh, S.E., Maillard, J.Y., Russell, A.D., Catrenich, C.E., Charbonneau, D.L., Bartolo, R.G. 2003. Activity and mechanisms of action of selected biocidal agents on Gram-positive and negative bacteria. J Appl Microbiol 94, 240-247.

Wang, H., Xue, Y., Zhang, H., Huang, Y., Yang, G., Du, M., Zhu, M.J. 2013. Dietary grape seed extract ameliorates symptoms of inflammatory bowel disease in IL10-deficient mice. Mol Nutr Food Res 57, 2253-2257.

Wang, Y.H., Ge, B., Yang, X.L., Zhai, J., Yang, L.N., Wang, X.X., Liu, X., Shi, J.C., Wu, Y.J. 2011. Proanthocyanidins from grape seeds modulates the nuclear factor-kappa B signal transduction pathways in rats with TNBS-induced recurrent ulcerative colitis. Int Immunopharmacol 11, 1620-1627.

Yang, G., Xue, Y., Zhang, H., Du, M., Zhu, M.J. 2015. Favourable effects of grape seed extract on intestinal epithelial differentiation and barrier function in IL10-deficient mice. Br J Nutr 114, $15-23$. 
478 Zhu, M.J., Olsen, S.A., Sheng, L., Xue, Y., Yue, W. 2015. Antimicrobial efficacy of grape seed 479 extract against Escherichia coli O157:H7 growth, motility and Shiga toxin production. Food 480 Control 51, 177-182.

481

482 

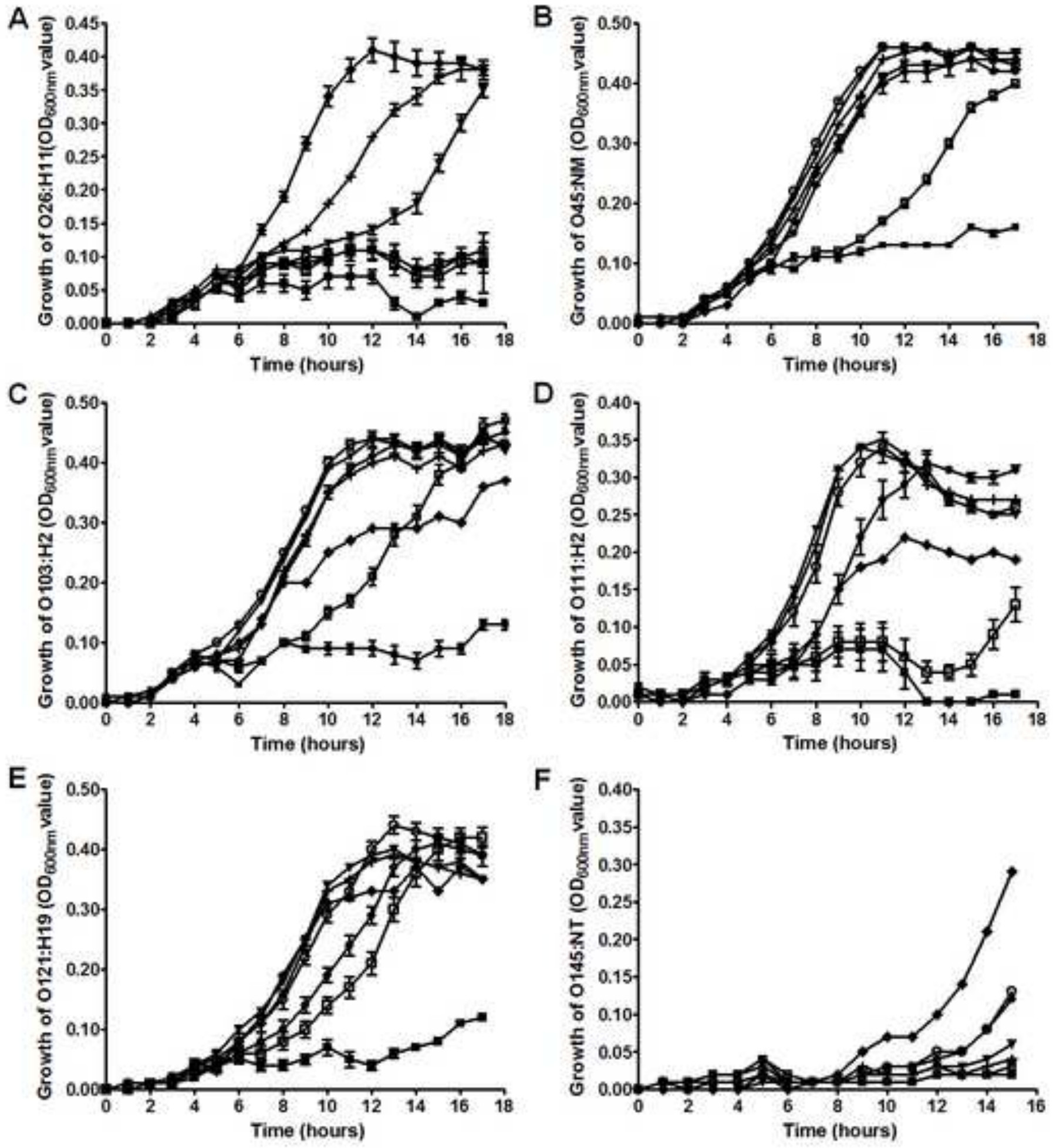

$\rightarrow 0+0.125 \rightarrow 0.25 \bullet 0.5 \leftarrow 1.0 \div 2.0 \div 4.0 \mathrm{mg} / \mathrm{ml}$ 

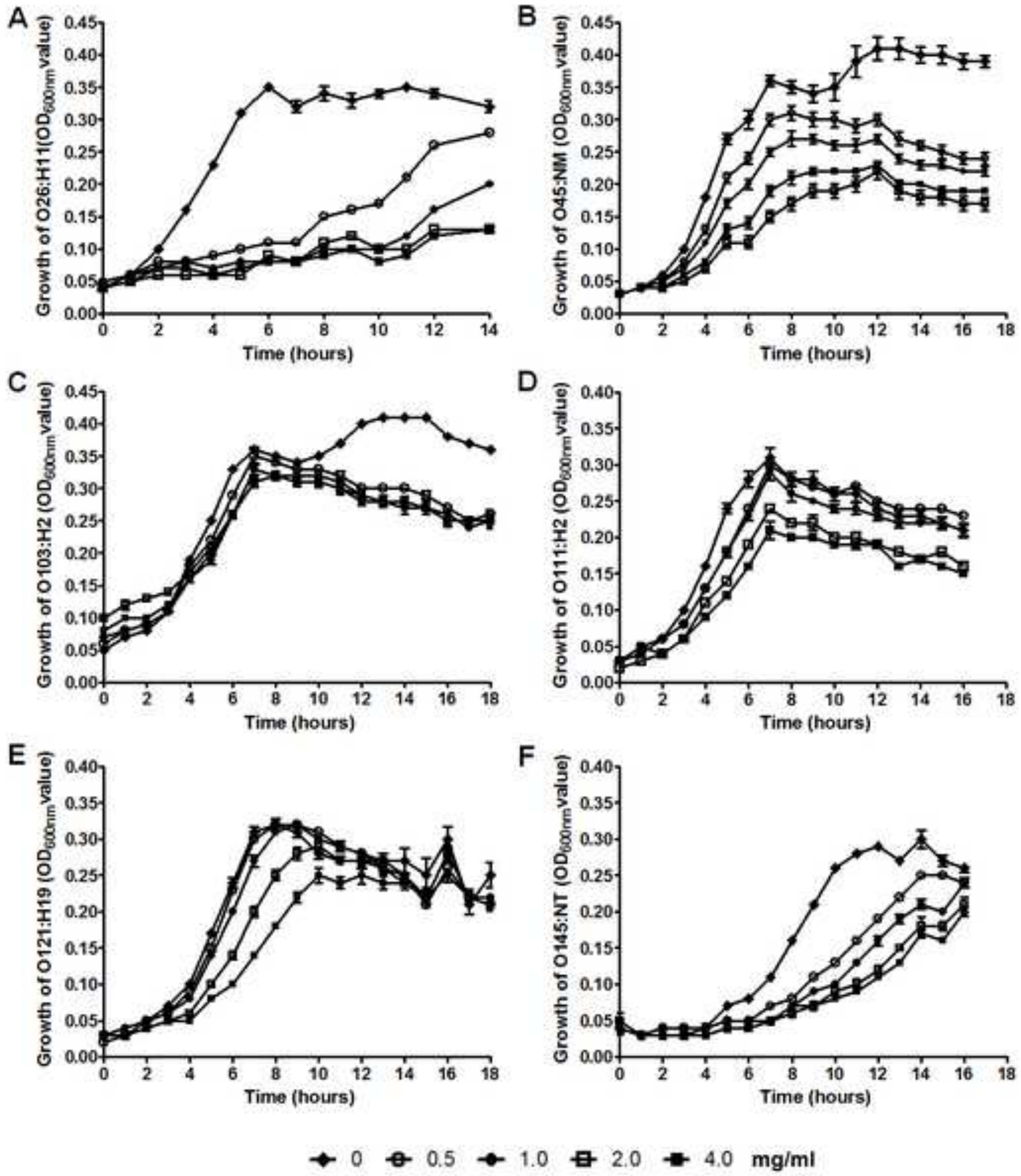
A
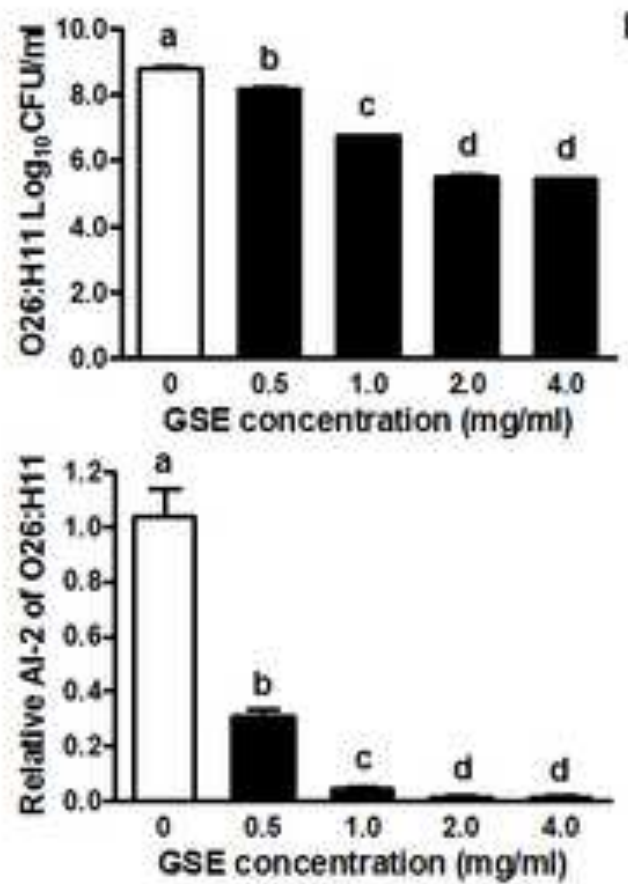

D
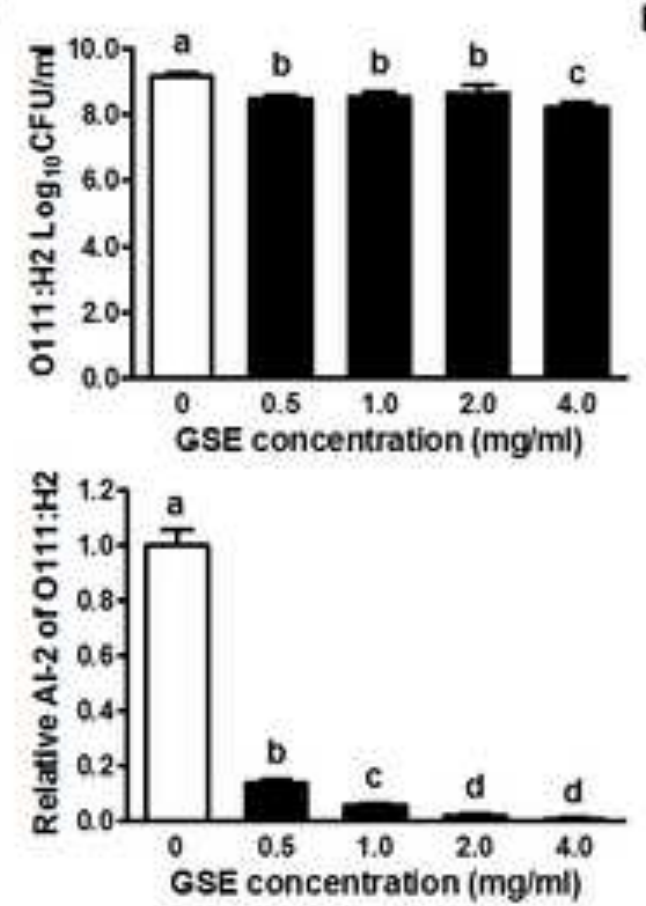

B
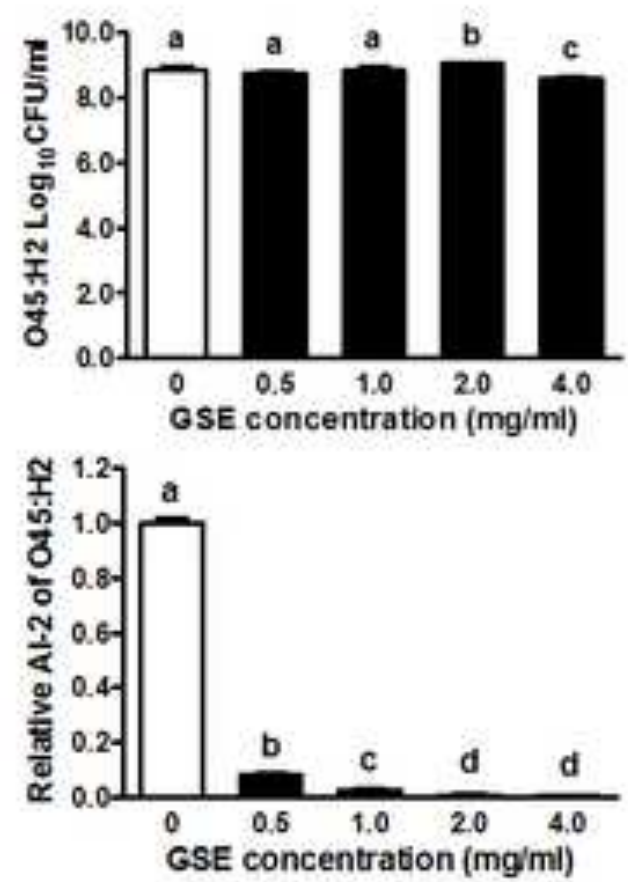

E
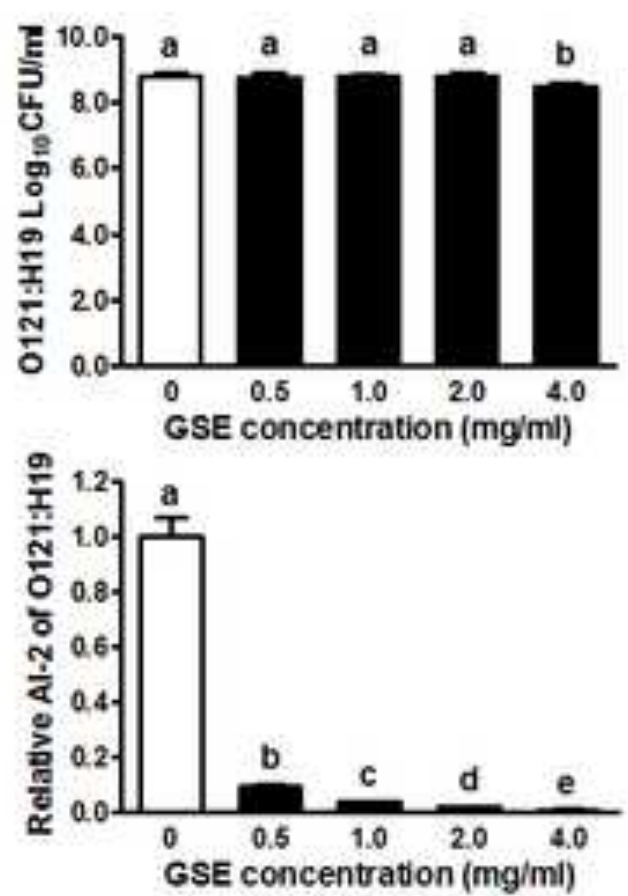

c
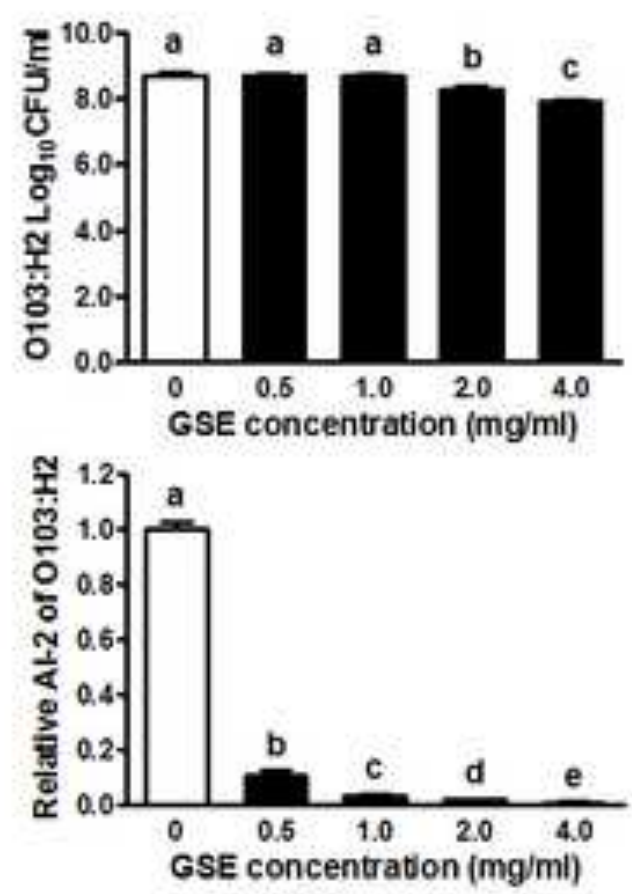

F
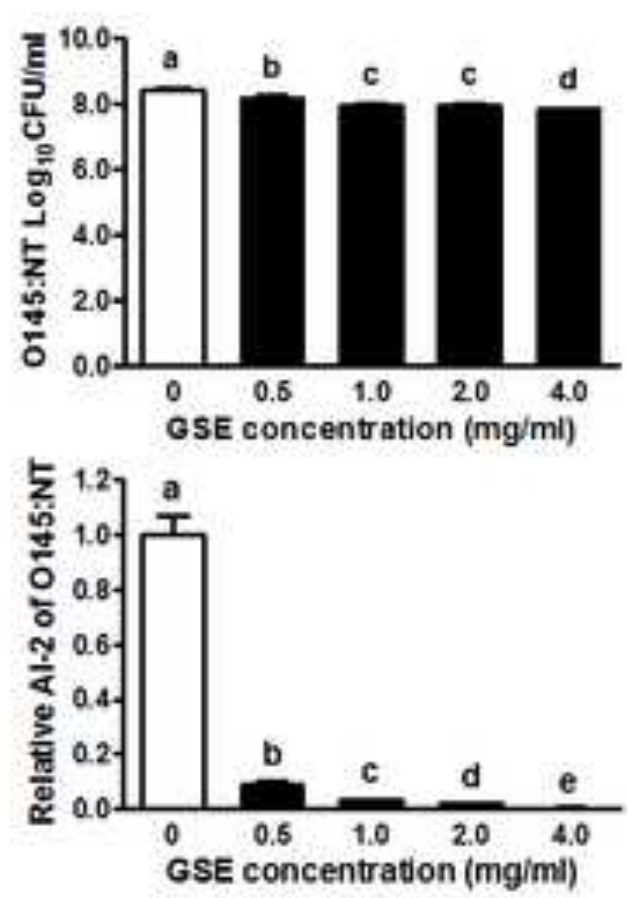

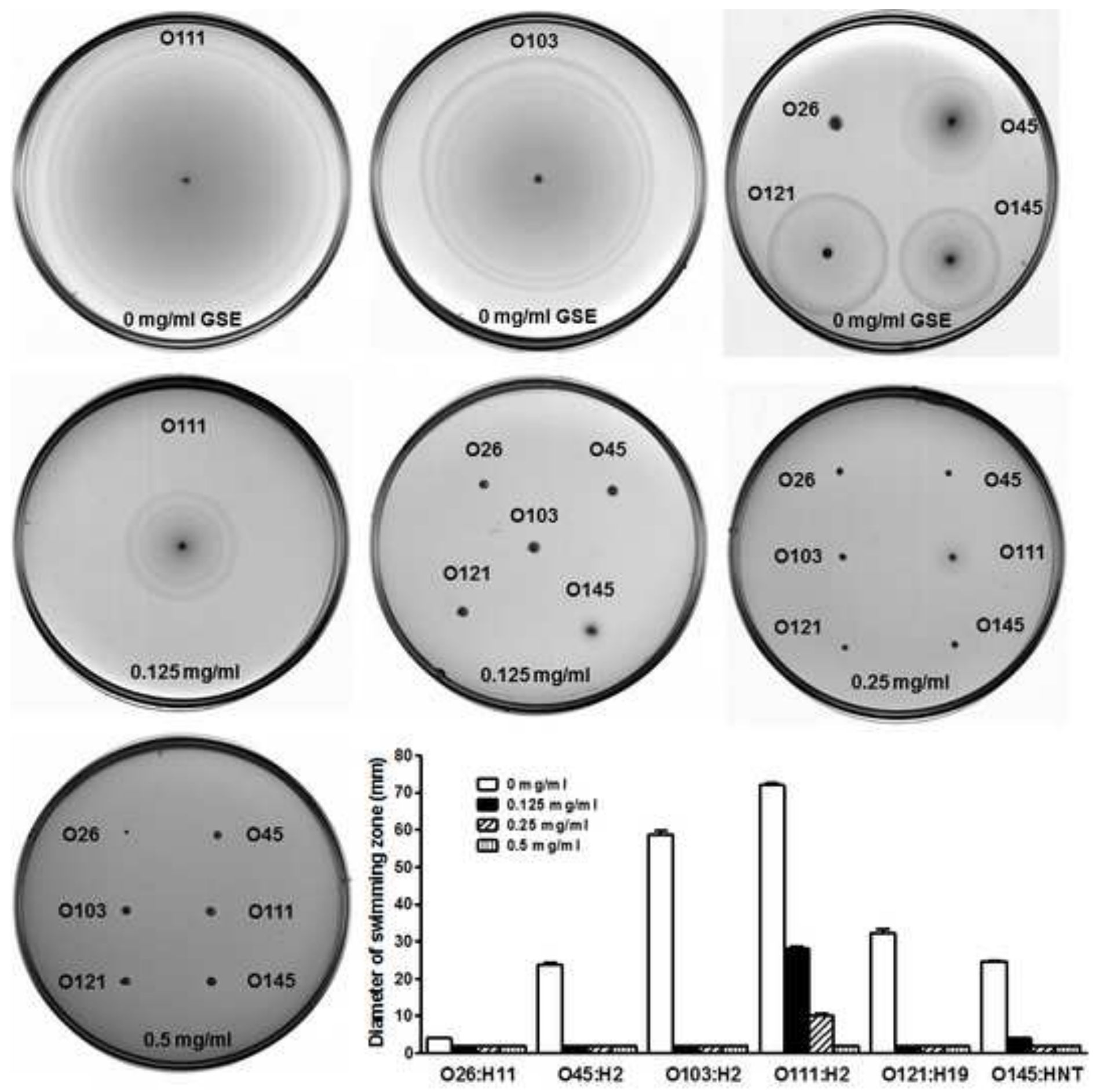
A
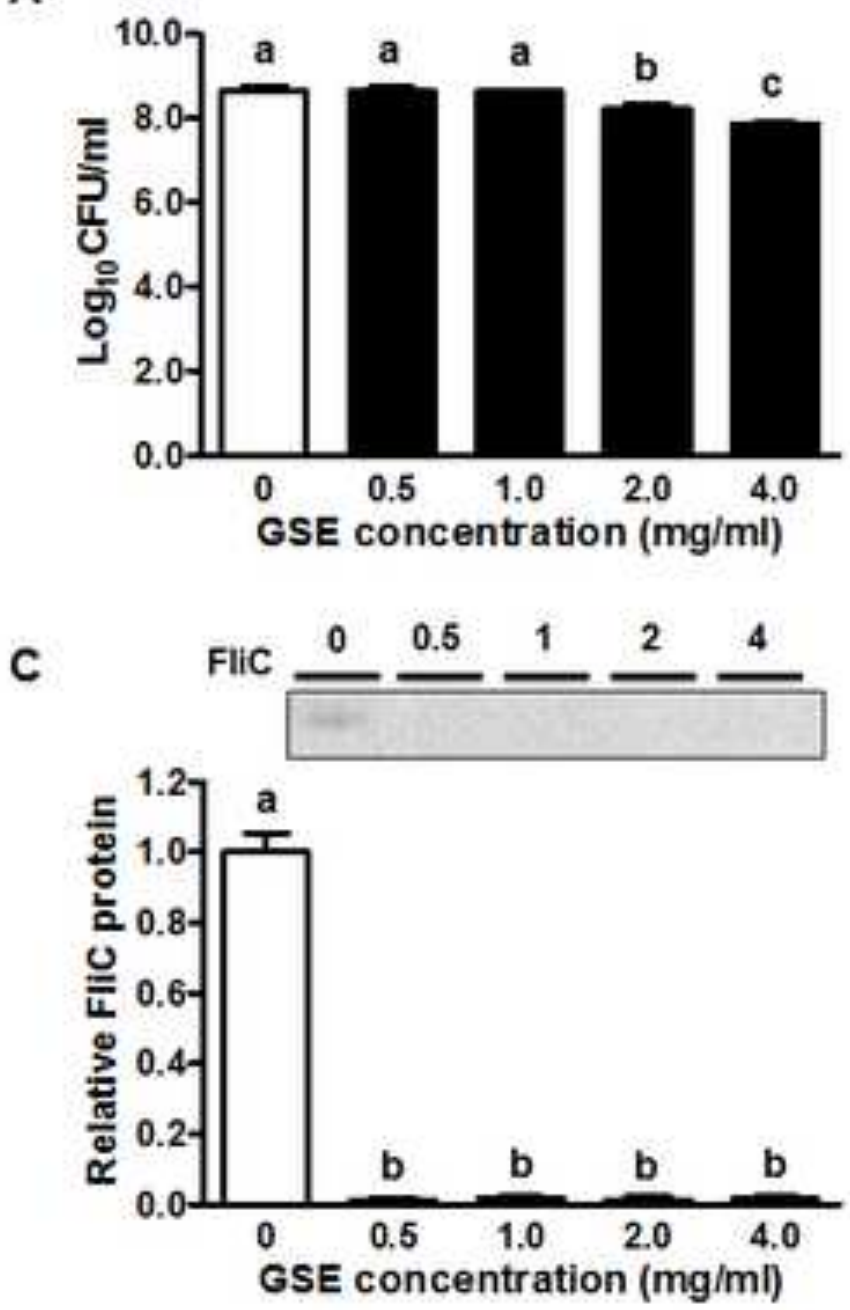

E

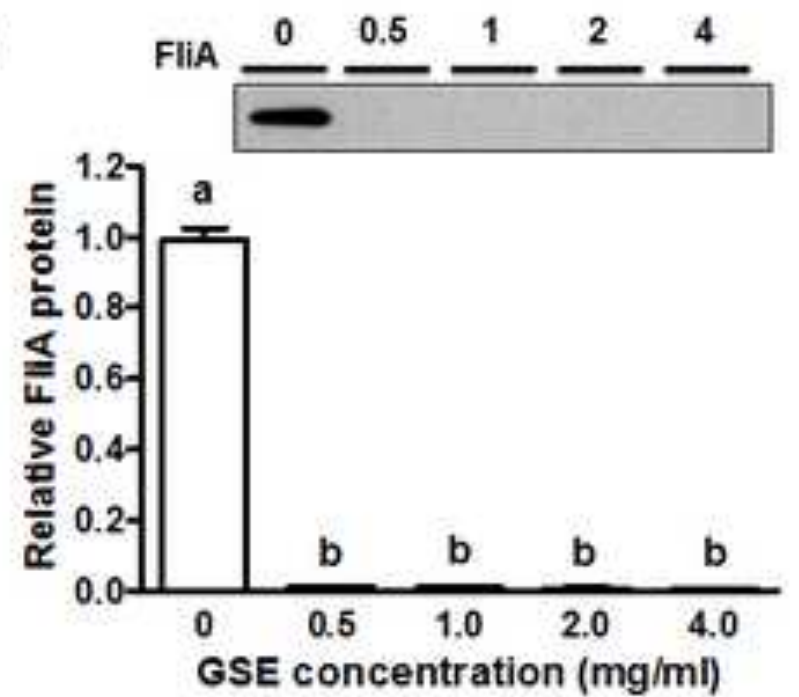

B

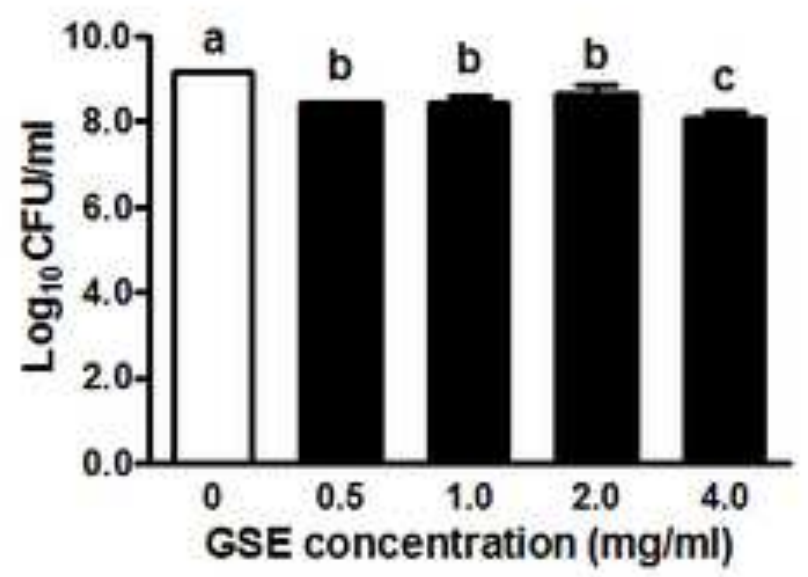

D

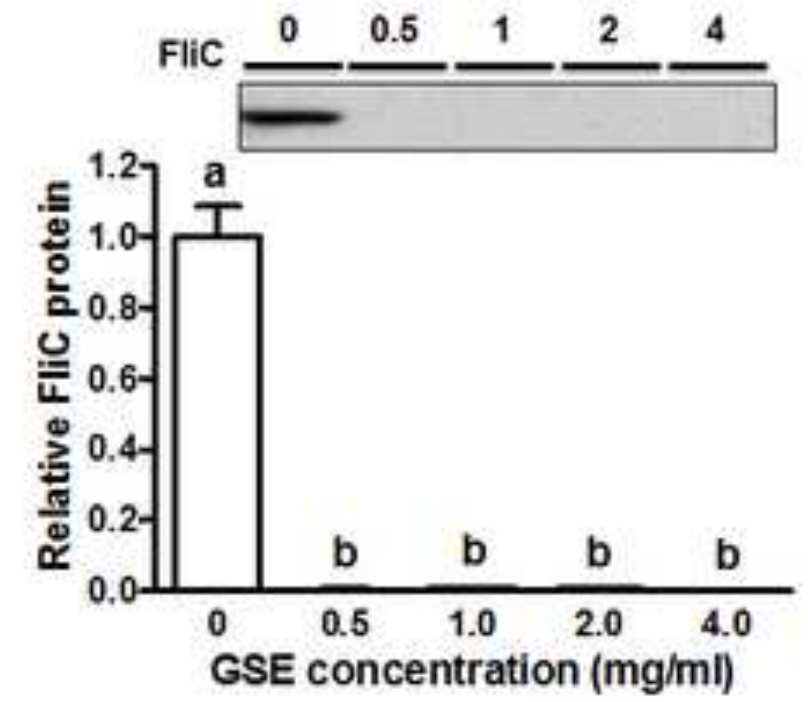

F

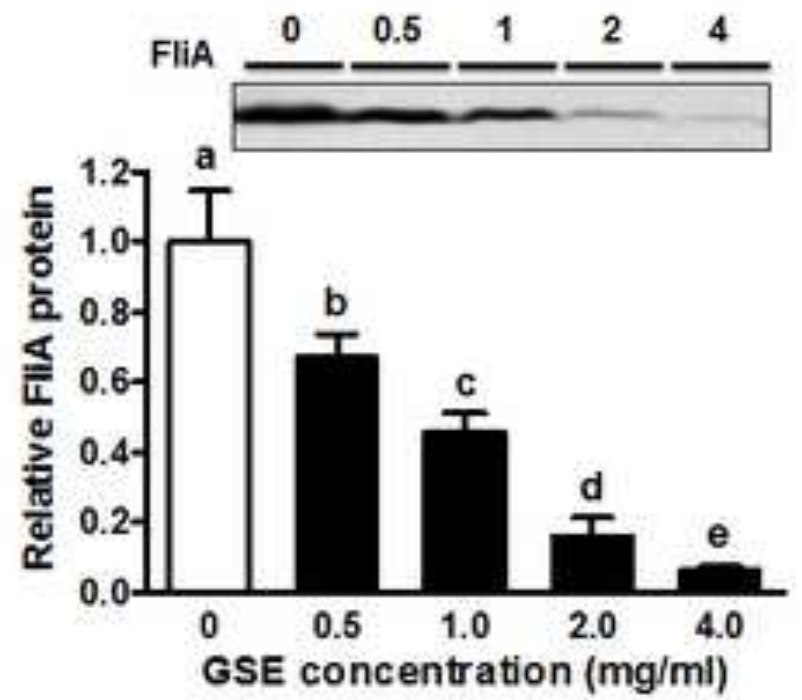


A

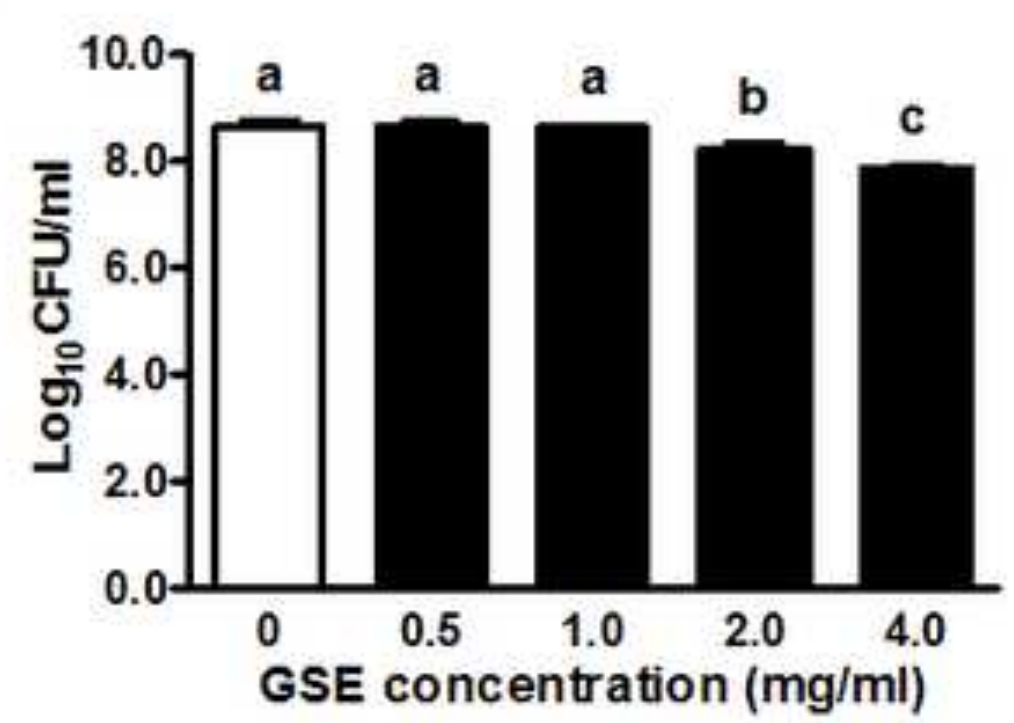

C

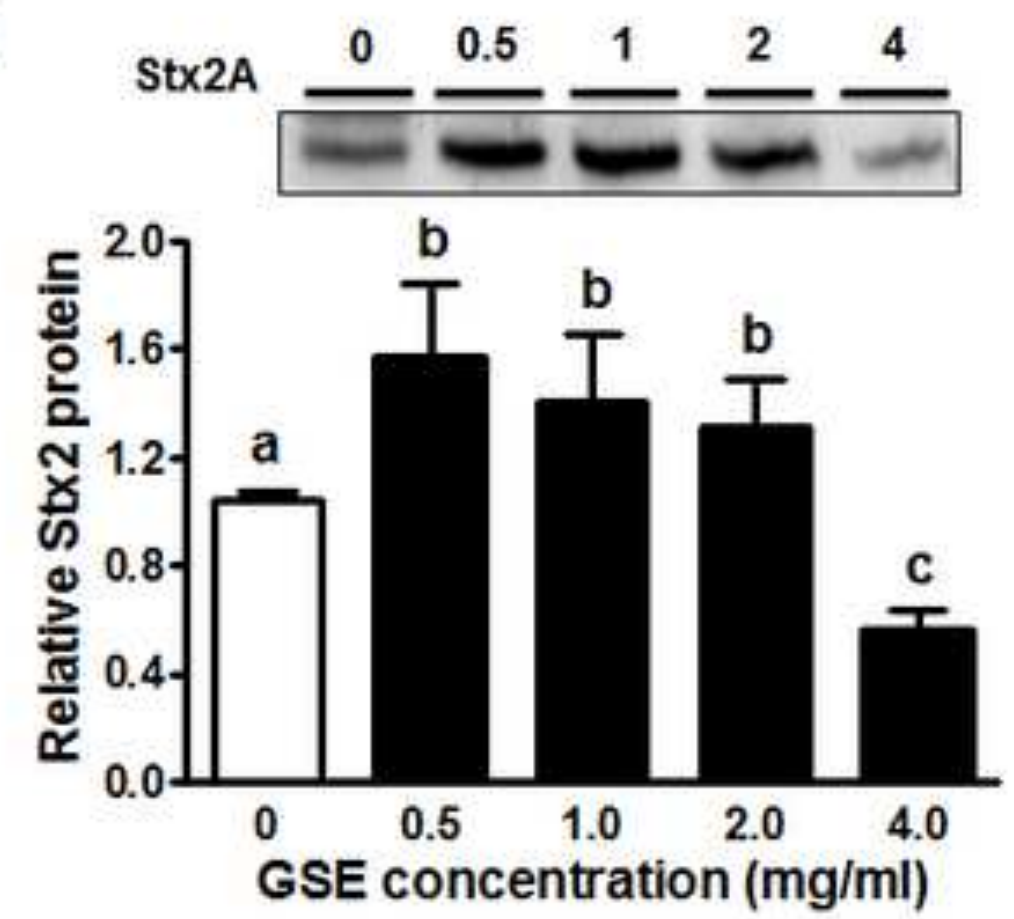

B

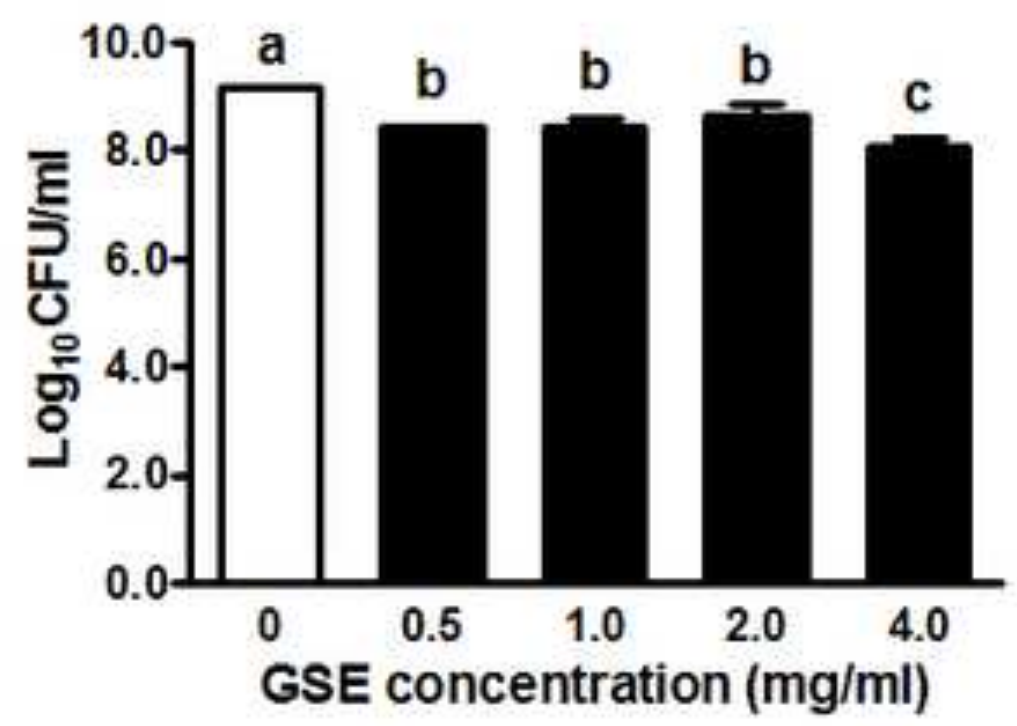

D

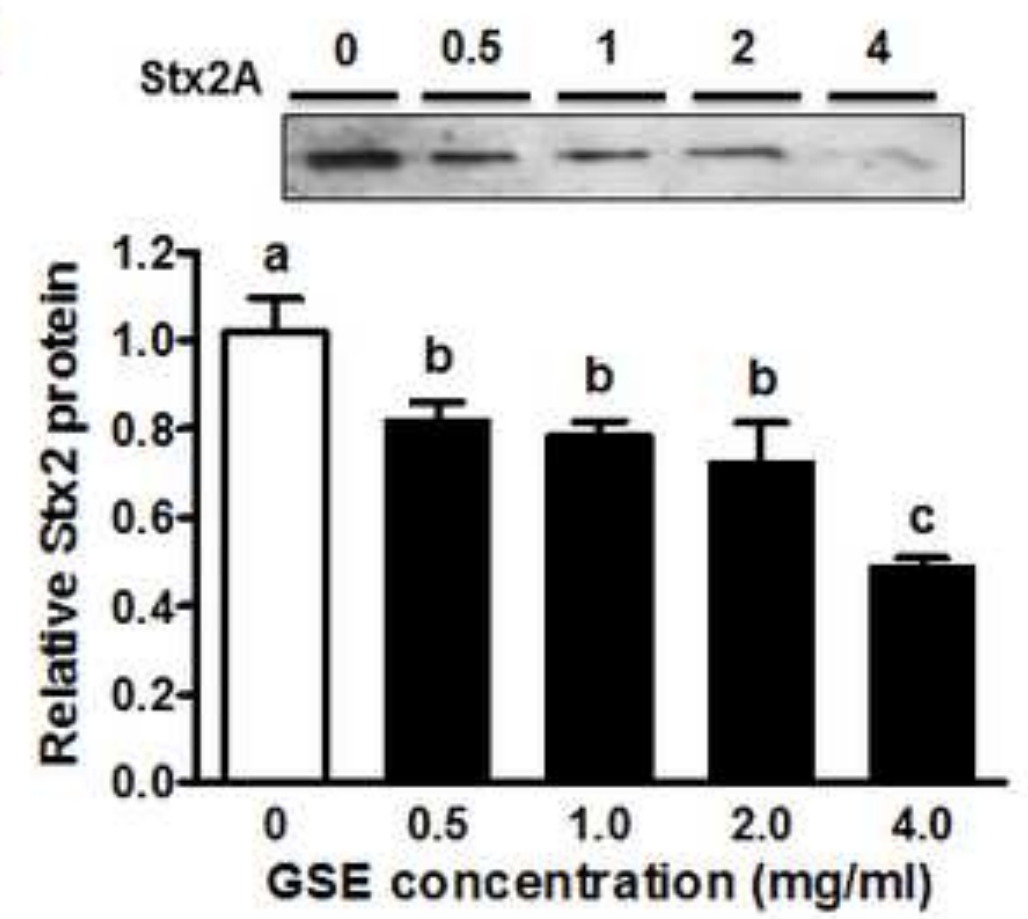

